\title{
Physical activity and ischaemic heart disease in middle-aged British men
}

\author{
A G Shaper, Goya Wannamethee
}

\begin{abstract}
Objective-To assess the relation between reported physical activity and the risk of heart attacks in middle aged British men.
\end{abstract}

Design-Prospective study of middleaged men followed for a period of eight years (The British Regional Heart Study).

Setting-One general practice in each of 24 British towns.

Participants-7735 men aged 40-59 years at initial examination.

End point-Heart attacks (non-fatal and fatal).

Measurements and main resultsDuring the follow up period of eight years 488 men suffered at least one major heart attack. A physical activity score used was developed and validated against heart rate and lung function $\left(F E V_{1}\right)$ in men without evidence of ischaemic heart disease. Risk of heart attack decreased significantly with increasing physical activity; the groups reporting moderate and moderately vigorous activity experienced less than half the rate seen in inactive men. The benefits of physical activity were seen most consistently in men without preexisting ischaemic heart disease and up to levels of moderately vigorous activity Vigorously active men had higher rates of heart attack than men with moderate or moderately vigorous activity. The relation between physical activity and the risk of heart attack seemed to be independent of other cardiovascular risk factors. Men with symptomatic ischaemic heart disease showed a reduction in the rate of heart attack at light or moderate levels of physical activity, beyond which the risk of heart attack increased. Men with asymptomatic ischaemic heart disease showed an increasing risk of heart attack with increasing levels of physical activity, but with a progressive decrease in case fatality. Overall, men who engaged in vigorous (sporting) activity of any frequency had significantly lower rates of heart attack than men who reported no sporting activity. However, when all men reporting regular sporting activity at least once a month were excluded from analysis, there remained a strong inverse relation between physical activity and the risk of heart attack in men without pre-existing ischaemic heart disease.

Conclusion-This study suggests that the overall level of physical activity is an important independent protective factor in ischaemic heart disease and that vigorous (sporting) exercise, although beneficial in its own right, is not essential in order to obtain such an effect.

There is considerable evidence that increased levels of physical activity are associated with lowered incidence rates of ischaemic heart disease. ${ }^{1}$ Particular attention has been paid to leisure time activity because few middle-aged men do physically demanding work and because, in public health terms, occupational activity is not amenable to change. Studies in British civil servants suggest that exercise is associated with a reduced risk of coronary events only when the exercise is both vigorous and sustained. ${ }^{2-4}$ This raises the important issue of whether lesser levels of physical activity have any effect on diminishing the risk of heart attack, an issue of considerable importance in a society in which regular vigorous activity is exceptional. Studies in the United States suggest that there is a continuous relation between physical activity and protection from heart attack. ${ }^{5-7}$ It has been suggested that this beneficial effect is largely mediated by the effects of physical activity on known coronary risk factors. ${ }^{8}$ In most studies, the relation has been examined in people free of clinical evidence of ischaemic heart disease and little is known about the long term effects of exercise in people with pre-existing evidence of ischaemic heart disease. The present paper examines the relation between physical activity and risk of heart attack in middle-aged men, drawn from general practices in 24 British towns, which are representative of the socioeconomic distribution of men in Great Britain. It includes men with pre-existing ischaemic heart disease.

\section{Subjects and methods}

The British Regional Heart Study is a large prospective study of cardiovascular disease comprising 7735 men aged $40-59$ selected from age-sex registers of one group general practice 
in each of 24 towns in England, Wales, and Scotland. The criteria for selecting the town, the general practice, and the subjects as well as the methods of data collection have been reported. ${ }^{9}$ Research nurses administered to each man a standard questionnaire that included questions on smoking habits, alcohol intake, physieal activity, and medical history. Several physical measurements were made and blood samples were taken for measurement of biochemical and haematological variables. Details of the measurement of serum lipid concentrations have been described. ${ }^{10}$ The men were classified according to their current smoking status into five groups: those who had never smoked, ex-cigarette smokers, and three groups of current smokers $(<20,20,>20$ cigarettes/day). Those who had only ever smoked pipe/cigars were grouped as "never smoked". Ex-cigarette smokers who currently smoked pipe/cigars were grouped as excigarette smokers. Alcohol consumption was recorded using questions on frequency, quantity, and type, similar to those used in the 1978 General Household Survey. Heavy drinkers were defined as those who regularly drank more than six drinks a day. The longestheld occupation of each man was recorded, and the men were grouped into one of six of the Registrar General's social classes: I, II, III non-manual, III manual, IV, and V. Men who had spent most of their working life in the armed forces form a separate group. For some analyses social classes I, II, and III nonmanual were combined as non-manual workers and social classes III manual, IV, and $\mathrm{V}$ as manual workers. Body mass index calculated as weight/height ${ }^{2}$ was used as an index of relative weight. Each man was weighed in trousers and socks to the nearest $0.1 \mathrm{~kg}$ on an MPS 110 field survey scale and height was measured without shoes to the nearest millimetre with a Harpenden Stadiometer with digital meter. Obesity was defined as $\geq 28 \mathrm{~kg} / \mathrm{m}^{2}$, which represents the top $20 \%$ of the body mass index distribution in these men. Heart rate was determined from the electrocardiogram. Forced expiratory volume in one second $\left(\mathrm{FEV}_{1}\right)$ was measured by a Vitalograph spirometer (model J49-B2) with the subject seated. Two consecutive readings were made 15 seconds apart and the maximum of these two readings was used. The $F E V_{1}$ values used in this paper are height standardised to $1.73 \mathrm{~m}$, the average height of the men in this study.

\section{BREATHLESSNESS}

A modified version of the Medical Research Council Questionnaire on Respiratory Symptoms (1966 version) was administered at the initial examination. Each man was asked: (a) Do you get short of breath walking with people your own age on ground level? (b) On walking up hills or stairs, do you get more breathless than people your own age? (c) Do you ever have to stop walking because of breathlessness? Each affirmative answer scored 1 , giving a possible score of $0-3$. Those who scored $\geq 1$ were defined as those reporting symptoms of breathlessness.
Table 1 Type and duration/frequency of physical activity with assigned scores and number of men

\begin{tabular}{lrr}
\hline Activity & Score & \multicolumn{1}{l}{$n$} \\
\hline Regular walking: & & \\
None & 0 & 4459 \\
$\leq 20$ min/weekday & 1 & 822 \\
$21-40$ & 2 & 941 \\
$41-60$ & 3 & 717 \\
$61-90$ & 4 & 162 \\
$>90$ & 5 & 79 \\
Recreational activity: & & \\
Very inactive & 0 & 333 \\
Fairly inactive & 1 & 906 \\
Average (4 h/weekend) & 3 & 2478 \\
Fairly active & 5 & 2086 \\
Very active & 7 & 1899 \\
Cycling: & & \\
None & 0 & 6759 \\
$\leq 15$ min/day & 2 & 64 \\
$16-30$ & 4 & 233 \\
$31-45$ & 6 & 110 \\
$46-60$ & 8 & 68 \\
$>1$ h & 10 & 23 \\
Sporting activity: & & \\
None & 0 & 4722 \\
Occ (<1 mnth) & 2 & 894 \\
$1-3$ times/mnth & 4 & 390 \\
$4-7$ & 8 & 764 \\
$8-11$ & 12 & 421 \\
$12-15$ & 16 & 233 \\
$16-19$ & 20 & 93 \\
$\geqslant 20$ & 24 & 190 \\
\hline
\end{tabular}

These categories are not mutually exclusive.

\section{PRE-EXISTING ISCHAEMIC HEART DISEASE}

The prevalence of ischaemic heart disease was measured in three ways at initial examination.

(a) The men were asked whether a doctor had ever told them that they had angina or myocardial infarction (heart attack, coronary thrombosis).

(b) The WHO (Rose) chest pain questionnaire for angina or possible myocardial infarction was administered to all men at the initial examination. ${ }^{11}$

(c) A three orthogonal lead electrocardiogram was recorded at rest and analysed by computer in the Department of Medical Cardiology, Glasgow Royal Infirmary.

The men were separated into three groups according to the degree of evidence of ischaemic heart disease present at screening.

(A) No evidence of ischaemic heart disease on WHO (Rose) chest pain questionnaire, electrocardiogram, or recall of a doctor diagnosis of ischaemic heart disease $(n=5767)$.

(B) Men with evidence suggesting ischaemic heart disease short of a definite myocardial infarction. This group contains those with electrocardiographic evidence of possible myocardial infarction and definite or possible myocardial ischaemia, those with angina or a possible myocardial infarction on WHO chest pain questionnaire, or those with recall of a doctor-diagnosis of angina $(n=1515)$.

(C) Men with evidence of a previous definite myocardial infarction on electrocardiogram or who recalled a doctor diagnosis of a heart attack $(n=428)$.

In the subsequent analyses men in groups $B$ and $C$ are regarded as having pre-existing ischaemic heart disease.

\section{PHYSICAL ACTIVITY}

The men were asked to indicate their usual pattern of physical activity, under the headings of regular walking or cycling, recreational 
activity, and sporting (vigorous) activity. A physical activity (exercise) score was derived for each man based on the frequency and type (intensity) of the physical activity. Scores were assigned for each type of activity and duration based on the intensity and energy demands of the activities reported (table 1 ). This was based on the recommendations of a National Heart, Lung and Blood Institute (NHLBI) workshop $^{12}$ and the Minnesota intensity codes. ${ }^{13}$ Scores were heavily weighted on vigorous exercise. Physical activity at work was excluded from the score partly because few middle-aged men do physically demanding work and partly because such activity is not readily amenable to modification. Though the gradings were arbitrary we tried to ensure that any given score implied approximately equal intensity and energy demands for the various types of activity. The total score for each man was not a measure of total time spent in physical activity but was a relative measure of how much physical activity has been carried out or energy expended. Regular walking and cycling related to weekday journeys, including those to and from work. Recreational activity includes gardening, pleasure walking, and do-it-yourself jobs. Sporting (vigorous) activity includes running, golf, swimming, tennis, sailing, digging, etc. It was not possible to identify the type of vigorous activity for each man (copies of the questionnaire are available on request) but it was regarded as being vigorous.

\section{PHYSICAL ACTIVITY INDEX}

The men were grouped into six broad categories based on their total score.

0-2 Inactive $(\mathrm{n}=686)$.

3-5 Occasional ( $n=2345$ ). Regular walking or recreational activity only.

6-8 Light $(\mathrm{n}=1761)$. More frequent recreational activities or vigorous exercise less than once a week.

9-12 Moderate $(\mathrm{n}=1205)$. Cycling or very frequent recreational activities or sporting activity once a week.

13-20 Moderately vigorous $(\mathrm{n}=1120)$. Sport-

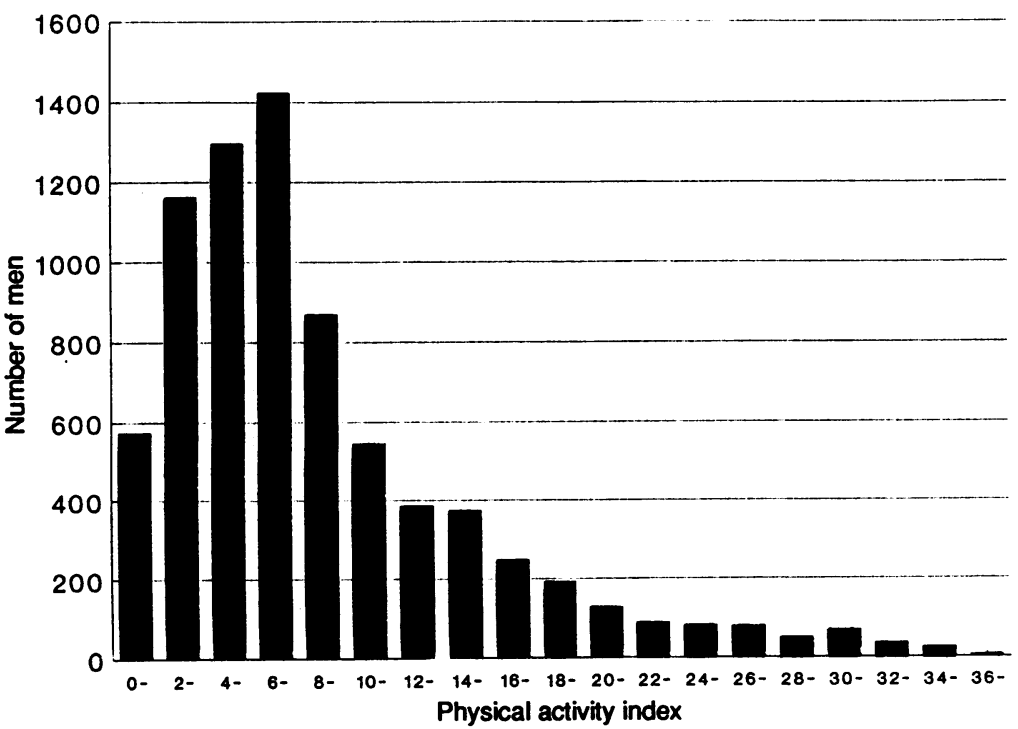

Figure 1 Distribution of physical activity index in 7630 men. ing activity at least once a week or frequent cycling, plus frequent recreational activities or walking; or frequent sporting activity only.

$\geq 21$ Vigorous $(\mathrm{n}=513)$. Very frequent sporting exercise or frequent sporting exercise plus other recreational activities.

\section{FOLLOW UP}

All men, whether or not they showed evidence of ischaemic heart disease at initial examination, were followed up for all cause mortality and cardiovascular morbidity. Information on death was collected through the established "tagging" procedures provided by the National Health Service registers in Southport (England and Wales) and Edinburgh (Scotland). Major ischaemic heart disease events (fatal and non-fatal) were based on an eight year period of follow up for all men. A non-fatal myocardial infarction was diagnosed according to WHO criteria. Fatal events were defined as death from ischaemic heart disease (International Classification of Disease 9th revision: codes $410-414)$ as the underlying cause. They comprised any ischaemic heart disease death in an individual during the eight year follow up irrespective of a previous nonfatal event during that period. Case fatality was defined as the proportion of the major ischaemic heart disease events in which death occurred during the first event during follow up and within 28 days and in which the death certificate recorded ischaemic heart disease (ICD codes 410-414).

\section{STATISTICAL METHODS}

Multiple logistic regression was used to obtain the rates adjusted for age, smoking, body mass index, and social class and the relative risks adjusting additionally for breathlessness, high density lipoprotein-cholesterol, total cholesterol, and systolic blood pressure. Age, body mass index, high density lipoproteincholesterol, total cholesterol, systolic blood pressure were fitted as continuous variables, physical activity as five dummy variables, smoking as four dummy variables (never, ex-, light, moderate and heavy), social class as two dummy variables (manual, non-manual and armed forces) and breathlessness as three dummy variables (none, light, moderate and severe). Tests for trend were assessed by assigning quantitative values $1-6$ for the six groups of physical activity and fitting physical activity as a continuous variable rather than as five dummy variables.

\section{Results}

Within the eight year follow up there were 488 major ischaemic heart disease events ("heart attacks") (fatal 217 and non-fatal 271). The physical activity total score was available for 7630 men. Some men did not provide details on all the components that contributed to the score ( $n=105$, including six who experienced a heart attack) and they have been excluded from analyses that use the total score. The total score 
Figure 2 Mean heart rate and $F E V$, according to physical activity index in 5714 men with no evidence of ischaemic heart disease. Means adjusted for age, body mass index, social class, and smoking status.

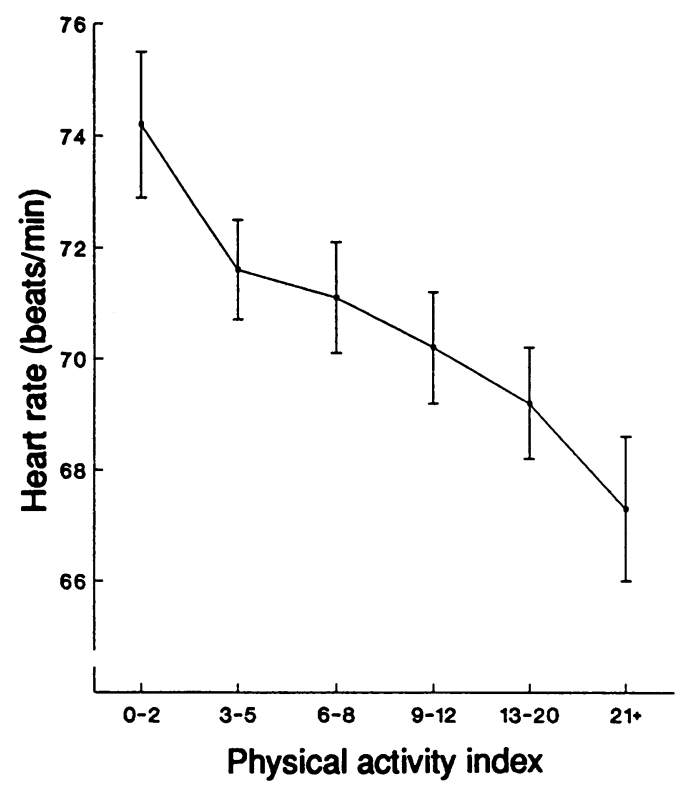

ranged from 0 to 41 with a median of 7 . Figure 1 shows the distribution of the score.

\section{VALIDITY OF THE SCORE}

It is well established that regular exercise improves physical fitness and lowers heart rate. Because heart rate is strongly influenced by the presence of pre-existing heart disease we examined the association between physical activity and heart rate in men with no evidence of ischaemic heart disease (fig 2). There was a strong association between physical activity and heart rate even after adjusting for age, body mass index, social class, and smoking, with heart rate decreasing significantly with increasing activity ( $p<0.0001)$.

$\mathrm{FEv}_{1}$ was also considered as a possible method of validating the physical activity index and it increased progressively with increasing physical activity $(\mathrm{p}<0.0001)$, even after adjusting for age, body mass index, social class, and smoking (fig 2). However, although ventilatory capacity is related to recreational activity, it is poorly correlated with other measures of physical fitness ${ }^{14}$ and validation in this study rests on the relation with heart rate.

PHYSICAL ACTIVITY AND HEART ATTACK

Figure 3 shows the crude and age adjusted heart attack rates for all men in the study separated into the six physical activity categories. Men who were inactive had a significantly higher attack rate than all other men and risk decreased significantly with increasing activity $(p<0.001)$. The apparent benefit of physical activity was most clearly seen in those who did moderate to vigorous activities (score $\geqslant 9$ ). These men had more than a $50 \%$ reduction in the risk of heart attack compared with men who were inactive.

PHYSICAL ACTIVITY AND PERSONAL

CHARACTERISTICS

Because physical activity is known to be associated with other health related behaviours and is also conditioned by ill health, we

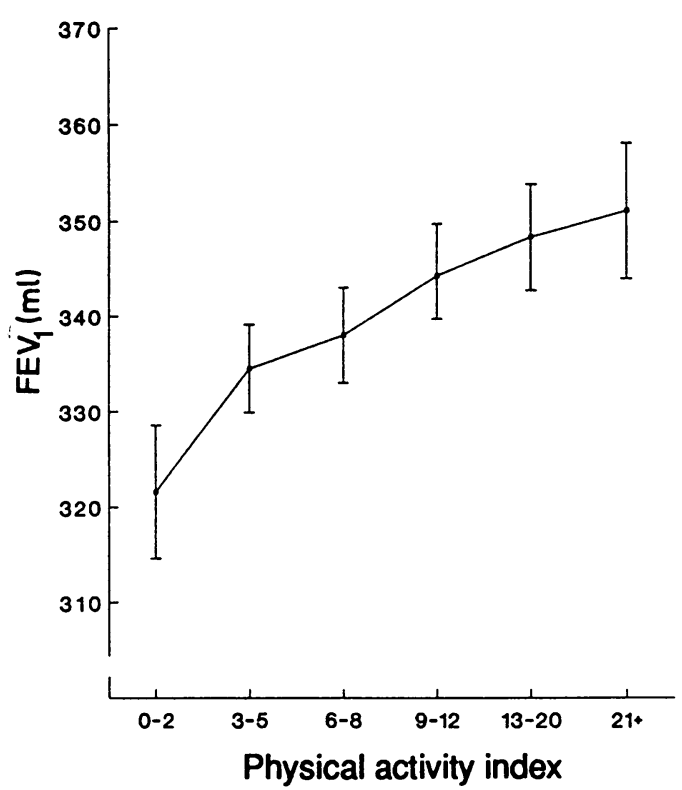

examined the personal characteristics and prevalence of ischaemic heart disease in the six physical activity categories (table 2). Those who were moderately active or more (score $\geq$ 9) tended to be younger and were more likely to be non-manual workers. There was little difference in age and social class between those who were inactive (0-2) and men who were occasionally or lightly active (score $3-8$ ). The proportion of current smokers decreased with increasing physical activity. The proportion of ex-smokers was similar in all groups. The proportion of men who had never smoked was highest in the most active group and decreased considerably towards those who are inactive. The proportion of obese men decreased progressively with increasing activity even though the mean body mass index only decreased slightly. Inactive men were more likely to be heavy drinkers ( $>6$ drinks daily)

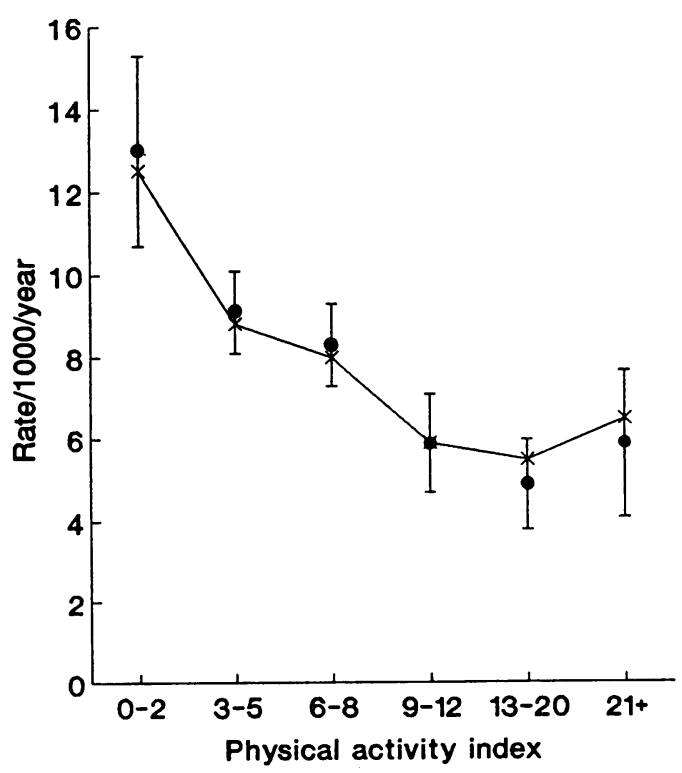

Figure 3 Heart attack rates (per 1000/year) according to physical activity index. Crude rates (O) with $95 \%$ confidence intervals and age adjusted rates $(x)$. 
Table 2 Personal characteristics and prevalence of ischaemic heart disease and breathlessness according to physical activity score

\begin{tabular}{|c|c|c|c|c|c|c|}
\hline & \multicolumn{6}{|c|}{ Physical activity index } \\
\hline & $0-2$ & $3-5$ & $6-8$ & $9-12$ & $13-20$ & $21+$ \\
\hline $\begin{array}{l}\text { No of men (\%) } \\
\text { No. IHD events }\end{array}$ & $\begin{array}{c}686(9) \\
71\end{array}$ & $\begin{array}{l}2345(31) \\
171\end{array}$ & $\begin{array}{l}1761(23) \\
116\end{array}$ & $\begin{array}{l}1205(16) \\
56\end{array}$ & $\begin{array}{c}1120(15) \\
44\end{array}$ & $\begin{array}{c}513(7) \\
24\end{array}$ \\
\hline $\begin{array}{l}\text { Age: } \\
\text { Mean } \\
\text { SE } \\
\% \text { 55-59 } \\
\% \text { Manual } \\
\% \text { Smoker: }\end{array}$ & $\begin{array}{l}50 \cdot 9 \\
(0 \cdot 22) \\
29 \\
67\end{array}$ & $\begin{array}{l}50 \cdot 8 \\
(0 \cdot 12) \\
28 \\
66\end{array}$ & $\begin{array}{l}50 \cdot 6 \\
(0 \cdot 14) \\
28 \\
64\end{array}$ & $\begin{array}{l}50 \cdot 1 \\
(0 \cdot 17) \\
27 \\
58\end{array}$ & $\begin{array}{l}48 \cdot 8 \\
(0 \cdot 17) \\
18 \\
47\end{array}$ & $\begin{array}{l}49 \cdot 0 \\
(0 \cdot 26) \\
20 \\
42\end{array}$ \\
\hline $\begin{array}{l}\text { Current } \\
\text { Ex } \\
\text { Never } \\
\text { Mean BMI: } \\
\text { SE } \\
\% \text { Obese } \\
\text { \% Heavy drinkers } \\
\text { \% IHD (any): } \\
\text { \%angina (Q) or recall }\end{array}$ & $\begin{array}{l}53 \\
32 \\
15 \\
25 \cdot 8 \\
(0 \cdot 15) \\
25 \\
16 \\
36\end{array}$ & $\begin{array}{l}44 \\
35 \\
19 \\
25 \cdot 7 \\
(0 \cdot 07) \\
22 \\
11 \\
27\end{array}$ & $\begin{array}{l}44 \\
33 \\
23 \\
25 \cdot 4 \\
(0 \cdot 08) \\
19 \\
11 \\
26\end{array}$ & $\begin{array}{l}40 \\
35 \\
25 \\
25 \cdot 3 \\
(0 \cdot 09) \\
16 \\
9 \\
23\end{array}$ & $\begin{array}{l}29 \\
38 \\
33 \\
25 \cdot 4 \\
(0 \cdot 08) \\
17 \\
9 \\
20\end{array}$ & $\begin{array}{l}28 \\
39 \\
33 \\
25 \cdot 0 \\
(0 \cdot 12) \\
13 \\
9 \\
16\end{array}$ \\
\hline $\begin{array}{c}\text { of angina (DR) } \\
\% \text { MI (ECG/DR) } \\
\text { Breathlessness: }\end{array}$ & $\begin{array}{l}25 \\
8 \cdot 8\end{array}$ & $\begin{array}{l}16 \\
6 \cdot 8\end{array}$ & $\begin{array}{l}15 \\
5 \cdot 1\end{array}$ & $\begin{array}{c}12 \\
4 \cdot 8\end{array}$ & $\begin{array}{l}10 \\
3.9\end{array}$ & $\begin{array}{l}7 \\
2 \cdot 2\end{array}$ \\
\hline $\begin{array}{l}\% \text { Any } \\
\% \text { Severe } \\
\end{array}$ & $\begin{array}{l}36 \cdot 9 \\
12 \cdot 3 \\
\end{array}$ & $\begin{array}{r}21 \cdot 4 \\
4 \cdot 3 \\
\end{array}$ & $\begin{array}{r}17.0 \\
2.5 \\
\end{array}$ & $\begin{array}{r}12 \cdot 0 \\
2 \cdot 1 \\
\end{array}$ & $\begin{array}{l}7.6 \\
1.0 \\
\end{array}$ & $\begin{array}{l}5 \cdot 3 \\
0 \cdot 2\end{array}$ \\
\hline
\end{tabular}

BMI, body mass index; DR, recall of doctor diagnosis; ECG, on electrocardiogram; IHD, ischaemic heart disease; MI, myocardial infarction; Q, on WHO (Rose) questionnaire.

but there was little difference between the other activity groups. There was a strong association between physical activity and presence of preexisting ischaemic heart disease, the prevalence tending to decrease with increasing physical activity. Those who were inactive had the highest prevalence of angina. The proportion of men with definite myocardial infarction decreased steadily as physical activity increased. The proportion of men reporting any degree of breathlessness, in particular severe breathlessness, decreased considerably with increasing activity. This is likely to be associated with both the high prevalence of ischaemic heart disease as well as the lack of physical fitness.

PHYSICAL ACTIVITY, AGE, AND HEART ATTACK The relation between physical activity and risk of heart attack was examined separately in those aged 40-49 and 50-59 after adjustment for smoking, social class, and body mass index (fig 4). In the older men being inactive was associated with a high rate of heart attack, suggesting the effect of pre-existing ischaemic heart disease. In younger men, those who were inactive had rates similar to occasionally or lightly active men. However, in both age groups moderate (9-12) to moderately vigorous (13-20) activities were associated with lower rates than inactive or occasionally active men. In younger men, those who were most active had a risk similar to the inactive, occasional, or lightly active men. In these men the risk of heart attack was significantly higher $(p=0.03)$ than in the moderately vigorous men. This was not seen for older men, and may reflect random variation or the type of sport undertaken. In these younger vigorously active men there was no undue increase in the proportion of sudden death.

PHYSICAL ACTIVITY AND PRE-EXISTING ISCHAEMIC HEART DISEASE

Because the presence and severity of ischaemic heart disease is likely to condition patterns of physical activity, we examined the relation separately in men with and without ischaemic heart disease, adjusting for age, social class, body mass index, and smoking (fig 5). In men without pre-existing ischaemic heart disease there was a strong inverse association between physical activity and heart attack up to levels of moderately vigorous activity $(\mathrm{p}<0.001)$. Those who were occasionally or lightly active showed a small decrease in risk of heart attack compared with inactive men. Those engaged in moderate or moderately vigorous activity had more than a $50 \%$ reduction in risk of heart attack compared with inactive men. The vigorously active men had a significant increase in risk compared with those who were engaged in moderate or moderately vigorous activity $(p=0.03)$. Because breathlessness has also

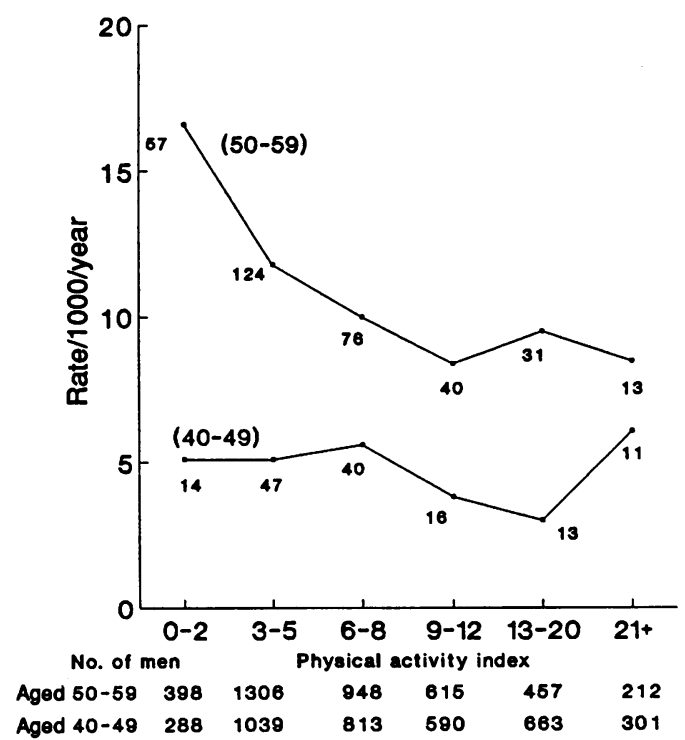

Figure 4 Heart attack rate (per 1000/year) in men aged 40-49 and 50-59 years according to physical activity index. Adjusted for body mass index, social class, and smoking. Number of heart attack events indicated on figure. 
Figure 5 Heart attack rates (per 1000/year) according to physical activity index in men with and without evidence of ischaemic heart disease. Adjusted for age, body mass index, social class and smoking. Number of heart attacks indicated on figure.

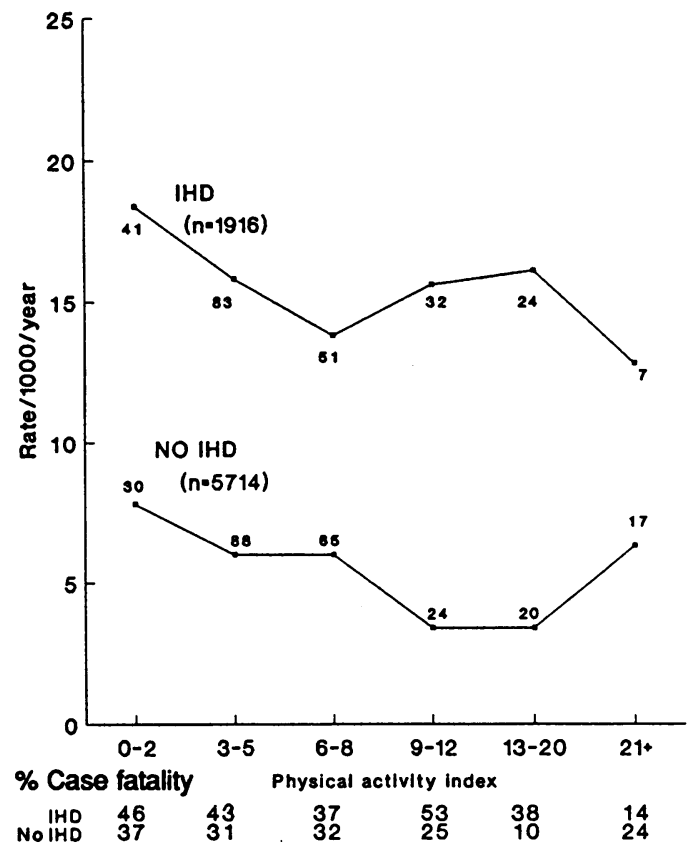

been shown to be a predictive factor for ischaemic heart disease ${ }^{15}$ and is strongly associated with physical activity (table 2) we examined the relation after adjusting for breathlessness as well. This made little difference to the association seen. Even exclusion of all men with any grade of breathlessness $(n=719)$ made no difference to the pattern seen in fig 5. Case fatality decreased as physical activity increased, with the lowest case fatality in the moderately vigorous men. It rose again in the vigorously active men.

In men with pre-existing ischaemic heart disease, inactive men showed the highest risk of heart attack but thereafter there was no consistent pattern in the risk of heart attacks with increasing levels of physical activity.

\section{SYMPTOMATIC AND ASYMPTOMATIC ISCHAEMIC HEART DISEASE}

The apparent absence of clear benefit from physical activity in men with pre-existing ischaemic heart disease may partly be due to men having modified their exercise pattern as a consequence of developing ischaemic heart disease. A few may increase their activity in an attempt to lower their risk of major events, but most are likely to decrease their physical activity because of chest pain or breathlessness. Physical exertion may also have different effects on people with various manifestations of ischaemic heart disease. We examined these possibilities further by dividing the 1916 men with evidence of ischaemic heart disease into two groups-those with objective measurements of ischaemic heart disease only (that is, those who did not report any chest pain but had ischaemic electrocardiographic abnormalities (asymptomatic) and those who reported angina or possible myocardial infarction on the WHO (Rose) questionnaire or who recalled a doctor diagnosis of myocardial infarction or angina, irrespective of electrocardiographic findings (symptomatic). The two groups are mutually exclusive. Because the numbers were small the moderately vigorous and vigorous activity groups (13-20 and 21 +) were combined (fig 6).

\section{SYMPTOMATIC ISCHAEMIC HEART DISEASE}

In each physical activity category the rate of heart attack was higher in the men with symptoms than in those without. Both light and moderate physical activity were associated with a lower heart attack rate than in inactive men but this difference was not statistically significant $(p=0 \cdot 1)$. At higher levels of physical activity, risk increased but again this difference was not statistically significant $(p=0 \cdot 1)$. Case fatality showed no particular pattern. The higher rates in the inactive and occasional activity group may partly reflect the severity of underlying ischaemic heart disease which determines the amount of physical activity possible. The prevalence of recall of a doctor diagnosis of ischaemic heart disease and of definite angina on WHO questionnaire were both higher in the inactive and occasionally active men combined than in the other three groups $(p=0.01)$. Electrocardiographic evidence of definite myocardial infarction did not differ systematically between the activity groups but definite myocardial ischaemia was least common in the light and moderately active men (6-8 and 9-12). Breathlessness was considerably increased in the inactive men with $44 \%$ reporting moderate or severe breathlessness compared with only $12 \%$ in the more vigorously active group $(\geq 13)$.

\section{ASYMPTOMATIC ISCHAEMIC HEART DISEASE}

There was an increase in the rate of heart attack with increasing physical activity up to the moderate activity level. Although the rate

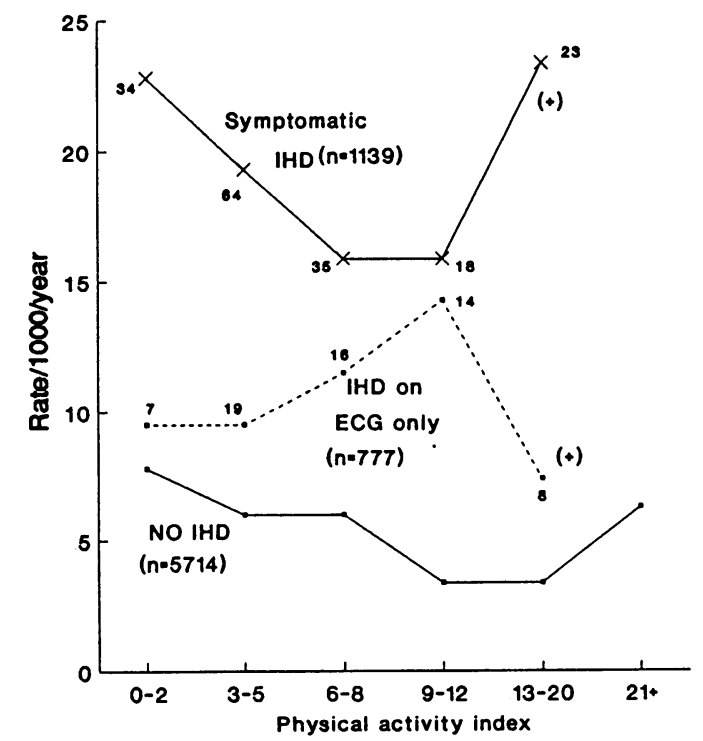

$\%$ Case fatality

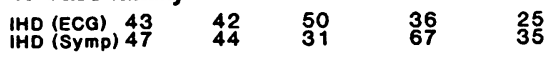

Figure 6 Heart attack rate (per 1000/year) according to physical activity index in men with symptomatic ischaemic heart disease, asymptomatic ischaemic heart disease, and in men without evidence of ischaemic heart disease. $(+)=13-20$ and $\geq 21$ combined. Adjusted for age, body mass index, social class, and smoking. Number of heart attacks indicated on figure. 
Table 3 Mean levels (SE) of risk factors according to physical activity index in men with no evidence of ischaemic heart disease

\begin{tabular}{|c|c|c|c|c|c|c|}
\hline & \multicolumn{6}{|c|}{ Physical activity index } \\
\hline & $0-2$ & $3-5$ & $6-8$ & $9-12$ & $13-20$ & $21+$ \\
\hline $\begin{array}{l}\text { No of men } \\
\text { Systolic blood pressure }(\mathrm{mm} \mathrm{Hg}) \text { : }\end{array}$ & 442 & 1706 & 1307 & 934 & 894 & 431 \\
\hline $\begin{array}{l}\text { Mean } \\
\text { SE } \\
\text { Adjusted for HR }\end{array}$ & $\begin{array}{l}143 \cdot 8 \\
(1 \cdot 00) \\
142 \cdot 7\end{array}$ & $\begin{array}{l}143 \cdot 0 \\
(0 \cdot 69) \\
142 \cdot 7\end{array}$ & $\begin{array}{l}142 \cdot 2 \\
(0 \cdot 74) \\
142 \cdot 0\end{array}$ & $\begin{array}{l}142 \cdot 1 \\
(0 \cdot 81) \\
142 \cdot 1\end{array}$ & $\begin{array}{l}141 \cdot 0 \\
(0 \cdot 84) \\
141 \cdot 3\end{array}$ & $\begin{array}{l}142 \cdot 5 \\
(1 \cdot 08) \\
143 \cdot 3\end{array}$ \\
\hline $\begin{array}{l}\text { Diastolic blood pressure }(\mathrm{mm} \mathrm{Hg}) \text { : } \\
\text { Mean } \\
\text { SE } \\
\text { Adjusted for } \mathrm{HR}\end{array}$ & $\begin{array}{c}82 \cdot 7 \\
(0 \cdot 65) \\
82 \cdot 1\end{array}$ & $\begin{array}{r}81 \cdot 2 \\
(0 \cdot 43) \\
81 \cdot 0\end{array}$ & $\begin{array}{c}80 \cdot 7 \\
(0 \cdot 47) \\
80 \cdot 6\end{array}$ & $\begin{array}{c}80 \cdot 5 \\
(0 \cdot 51) \\
80 \cdot 5\end{array}$ & $\begin{array}{r}79 \cdot 7 \\
(0 \cdot 53) \\
79 \cdot 9\end{array}$ & $\begin{array}{r}80 \cdot 6 \\
(0 \cdot 68) \\
81 \cdot 1\end{array}$ \\
\hline $\begin{array}{l}\text { Cholesterol }(\mathrm{mmol} / \mathrm{l}): \\
\text { Mean } \\
\text { SE }\end{array}$ & $\begin{array}{c}6.36 \\
(0.06)\end{array}$ & $\begin{array}{c}6.40 \\
(0.04)\end{array}$ & $\begin{array}{c}6.37 \\
(0.04)\end{array}$ & $\begin{array}{c}6.27 \\
(0.04)\end{array}$ & $\begin{array}{c}6.35 \\
(0.04)\end{array}$ & $\begin{array}{r}6.30 \\
(0.06)\end{array}$ \\
\hline $\begin{array}{l}\text { HDL cholesterol (mmol/l): } \\
\text { Mean } \\
\text { SE }\end{array}$ & $\begin{array}{l}1 \cdot 15 \\
(0.01)\end{array}$ & $\begin{array}{c}1.14 \\
(0.01)\end{array}$ & $\begin{array}{c}1.15 \\
(0.01)\end{array}$ & $\begin{array}{c}1.15 \\
(0.01)\end{array}$ & $\begin{array}{c}1.17 \\
(0.01)\end{array}$ & $\begin{array}{c}1.19 \\
(0.01)\end{array}$ \\
\hline
\end{tabular}

All relations adjusted for age, body mass index, social class, and smoking state.

HDL, high density lipoprotein; HR, heart rate.

seemed to fall in the more vigorously active men ( $>13$ ) the numbers were small. Case fatality was lowest in the most active men. The prevalence of definite myocardial infarction and of definite myocardial ischaemia did not differ in any systematic way between the physical activity groups. Breathlessness (grades 2 and 3 combined) declined from a prevalence of $20.2 \%$ in the inactive to $3.8 \%$ in the moderately vigorous and vigorously active men. Because this did not relate to the electrocardiographic evidence of myocardial damage it is likely to reflect their degree of physical fitness.

SOCIAL CLASS AND HEART ATTACK

The relation between physical activity and heart attack in men without evidence of ischaemic heart disease was similar in both social classes. Those who carried out moderate or moderately vigorous activity (13-20) showed a large reduction in the risk of heart attack. Risk increased in those in the vigorous activity group in both social classes (data not presented).

\section{PHYSICAL ACTIVITY AND RISK FACTORS}

Several studies have suggested that exercise is positively associated with a more favourable risk factor state. Because those with pre-existing ischaemic heart disease are likely to have a greater frequency of adverse risk factors and because the presence of ischaemic heart disease may lead to changes being made in risk factor state, we examined the relation between physical activity and blood pressure and blood lipids in men with no evidence of ischaemic heart disease after adjusting for age, body mass index, social class, and smoking (table 3). There was a tendency for blood pressure to decrease with increasing activity, the decrease being greater for diastolic than for systolic ( $p=0.04$ and $p<0.01$ respectively) However, in the most active group blood pressures increased slightly. Because physical activity is strongly and inversely associated with heart rate, which is also correlated with systolic and diastolic blood pressure $(r=0.2$, $\mathrm{p}<0.0001$ and $\mathrm{r}=0.18, \quad \mathrm{p}<0.0001$ respectively), adjustments were made for heart rate. The association between physical activity and systolic blood pressure was no longer significant. The association with diastolic blood pressure was reduced considerably but remained significant $(p=0.03)$. Physical activity showed no association with total cholesterol concentration but there was a tendency for high density lipoprotein cholesterol to rise with increasing physical activity $(\mathrm{p}<0.01)$. However, high density lipoprotein cholesterol was raised significantly (by 3\%) only in the men who were vigorously active.

To assess whether the beneficial effect of physical activity on risk of heart attack is mediated in part by its influence on risk factors (tables 2 and 3) we examined the relation in men without ischaemic heart disease, adjusting as previously for age, body mass index, social class, and smoking status (see fig 5) and then, in addition, for systolic blood pressure, blood lipids, $\mathrm{FEV}_{1}$, breathlessness, and heart rate. Heart rate has been shown in some studies to be associated with an increased risk of coronary heart disease independent of other risk factors. ${ }^{16}$ The findings are presented in terms of relative risks (table 4 ). After the additional adjustment there was only a small reduction in risk in those who were occasionally or lightly active compared with inactive men. Men who were moderately active or who undertook moderately vigorous activity still showed a significant reduction in the risk of heart attacks. The vigorously active men had the most favourable risk factor state overall, and yet after

Table 4 Adjusted relative risk (and 95\% confidence intervals) of heart attack according to physical activity index in 5714 men without pre-existing ischaemic heart disease

\begin{tabular}{lll}
\hline $\begin{array}{l}\text { Physical activity } \\
\text { index }\end{array}$ & Adjusted & $\begin{array}{l}\text { Adjusted } \dagger \\
\text { in addition }\end{array}$ \\
\hline $0-2$ & 1.0 & 1.0 \\
$3-5$ & $0.8(0.5$ to 1.2$)$ & $0.9(0.5$ to 1.3$)$ \\
$6-8$ & $0.8(0.5$ to 1.2$)$ & $0.9(0.6$ to 1.4$)$ \\
$9-12$ & $0.4(0.2$ to 0.8$)$ & $0.5(0.2$ to 0.8$)$ \\
$13-20$ & $0.4(0.2$ to 0.8$)$ & $0.5(0.3$ to 0.9$)$ \\
$21+$ & $0.8(0.4$ to 1.4$)$ & $0.9(0.5$ to 1.8$)$ \\
\hline
\end{tabular}

* Adjusted for age, body mass index, social class, and smoking

$†$ Adatus. †djusted in addition for systolic blood pressure, total
cholesterol, HDL cholesterol, FEV $_{1}$, breathlessness, and heart rate. 
Table 5 Type and duration/frequency of physical activity, number of men and cases of heart attack, and heart attack rates (per 1000/year) in men with and without pre-existing ischaemic heart disease

\begin{tabular}{|c|c|c|c|c|}
\hline \multirow[b]{2}{*}{ Physical activity } & \multirow[b]{2}{*}{ No $(\%)$ of men } & \multirow[b]{2}{*}{ No of cases } & \multicolumn{2}{|c|}{ Rate/1000/year * } \\
\hline & & & No IHD & $I H D$ \\
\hline $\begin{array}{l}\text { Regular walking: } \\
\text { None } \\
\leq 20 \mathrm{~min} / \text { weekday } \\
21-40 \\
41-60 \\
>1 \text { hour }\end{array}$ & $\begin{array}{l}4676(61) \\
860(11) \\
996(13) \\
828(10) \\
305(4)\end{array}$ & $\begin{array}{r}301 \\
53 \\
62 \\
45 \\
24\end{array}$ & $\begin{array}{l}5 \cdot 5(3510) \\
5 \cdot 4(647) \\
5 \cdot 5(762) \\
3 \cdot 6(602) \\
6 \cdot 0(221)\end{array}$ & $\begin{array}{l}15 \cdot 6(1166) \\
14 \cdot 8(213) \\
14 \cdot 4(234) \\
14 \cdot 4(226) \\
20 \cdot 6(84)\end{array}$ \\
\hline $\begin{array}{l}\text { Regular cycling: } \\
\text { None } \\
\leq 30 \mathrm{~min} \\
>30\end{array}$ & $\begin{array}{c}7205(93) \\
294(4) \\
207(3)\end{array}$ & $\begin{array}{r}459 \\
16 \\
10\end{array}$ & $\begin{array}{l}5.4(5378) \\
4.4(224) \\
4.9(171)\end{array}$ & $\begin{array}{l}15 \cdot 5(1827) \\
15 \cdot 1(70) \\
12 \cdot 4(36)\end{array}$ \\
\hline $\begin{array}{l}\text { Recreational activity: } \\
\text { Inactive } \\
\text { Fairly inactive } \\
\text { Average } \\
\text { Fairly active } \\
\text { Very active }\end{array}$ & $\begin{array}{c}333(4) \\
906(12) \\
2478(32) \\
2086(27) \\
1899(25)\end{array}$ & $\begin{array}{r}35 \\
76 \\
151 \\
125 \\
98\end{array}$ & $\begin{array}{l}8 \cdot 0(194) \\
6 \cdot 8(658) \\
5 \cdot 3(1847) \\
5 \cdot 1(1593) \\
5 \cdot 0(1474)\end{array}$ & $\begin{array}{l}17 \cdot 3(139) \\
19 \cdot 3(248) \\
15 \cdot 1(631) \\
15 \cdot 8(493) \\
12 \cdot 8(425)\end{array}$ \\
\hline $\begin{array}{l}\text { Sporting exercise: } \\
\text { None } \\
\text { Occasionally } \\
1-3 \text { times/mnth } \\
4-7 \\
8-11 \\
\geq 12\end{array}$ & $\begin{array}{l}4722(61) \\
894(12) \\
400(5) \\
770(10) \\
421(6) \\
517(4)\end{array}$ & $\begin{array}{r}354 \\
47 \\
12 \\
30 \\
16 \\
16\end{array}$ & $\begin{array}{l}6 \cdot 1(3401) \\
4 \cdot 1(672) \\
1 \cdot 8(333) \\
4 \cdot 1(615) \\
3 \cdot 5(335) \\
5 \cdot 9(428)\end{array}$ & $\begin{array}{l}15 \cdot 1(1321) \\
15 \cdot 1(222) \\
18 \cdot 0(67) \\
14 \cdot 8(155) \\
13 \cdot 1(86) \\
20 \cdot 4(89)\end{array}$ \\
\hline
\end{tabular}

^Adjusted for age, body mass index, social class, and smoking state.

adjustment the risk of heart attack was only slightly lower than that seen in men who were inactive.

\section{TYPES OF ACTIVITY AND HEART ATTACK}

The physical activity index provides a relative measure of overall physical activity. It was of interest to see whether any specific type of activity was most associated with a beneficial effect. "Recreational" work was the most frequent type of leisure activity (table 5) among this population of middle aged British men. Eighty four per cent of the men reported spending at least four hours gardening/ pleasure walking or do-it-yourself work over the weekend. Thirty six per cent of the men did regular walking on weekdays. Twenty five per cent of the men were engaged in regular physical sporting activities (at least once a month) and only $7 \%$ cycled regularly.

The attack rate adjusted for age, social class, smoking, and body mass index by the different types of physical activity is shown in table 4 separately in men with and without ischaemic heart disease. These activities are not mutually exclusive. Regular walking was not significantly associated with the risk of heart attack, though in men without ischaemic heart disease those who walked 41-60 minutes a day to and from work (more than a mile each time at fast pace) showed a decreased risk compared with other men $(p=0.06)$. In men with ischaemic heart disease regular walking seemed to have little

Table 6 Relative risk of heart attack in men with and without pre-existing ischaemic heart disease according to physical activity index excluding all men engaged in sporting activity at least once a month

\begin{tabular}{lcllll}
\hline & \multicolumn{2}{l}{ No IHD } & & \multicolumn{1}{l}{ IHD } \\
\cline { 2 - 3 } \cline { 5 - 6 } Physical activity & No & $R R(95 \% C I)$ & & No & $R R(95 \% C I)$ \\
\hline $0-2$ & 442 & 1.0 & & 244 & 1.0 \\
$3-5$ & 1685 & $0.8(0.5$ to 1.2$)$ & & 633 & $0.8(0.5$ to 1.2$)$ \\
$6-8$ & 1210 & $0.8(0.5$ to 1.2$)$ & & 434 & $0.7(0.4$ to 1.1$)$ \\
$9-12$ & 589 & $0.4(0.2$ to 0.8$)$ & & 187 & $0.8(0.5$ to 1.4$)$ \\
$Z 13$ & 93 & $0.3(0.2$ to 1.3$)$ & & 24 & $0.9(0.3$ to 3.3$)$ \\
\hline
\end{tabular}

*Adjusted for age, body mass index, social class, and smoking state. effect on heart attack rate. The increased rate in those with the longest duration of walking was not significantly different from the rest. In men without ischaemic heart disease cycling was associatied with a small (non-significant) reduction in risk. The number of men with ischaemic heart disease who cycled was too small to draw any inference. Recreational activity was associated with a reduced rate of heart attack in both men with and without ischaemic heart disease. The risk decreased progressively from those who reported being very inactive to those who reported being at least average. This trend was significant for men without ischaemic heart disease $(p=0.04)$ but did not reach significance in those with evidence of ischaemic heart disease. Sporting exercise was significantly associated with a decreased risk in heart attack in men with no previous ischaemic heart disease. Overall, those who did any regular sporting exercise had lower rates than those who did no sporting exercise but the rate did not decrease progressively with increasing frequency of sporting activity. The lowest rates were seen in those who did sporting exercise less than three times a month. Somewhat surprisingly, those who played very frequent sports shared a similar rate to those who did no sporting activity. In men with ischaemic heart disease very frequent sporting exercise $(>12)$ was associated with a non-significant increase in risk of heart attack.

RISK OF HEART ATTACK AFTER EXCLUSION OF SPORTING ACTIVITY

Morris and his colleagues have indicated that it is only regular sporting exercise that is associated with reduced rates of heart attack, ${ }^{2-4}$ whereas others have shown that frequent light or moderate activity is sufficient to produce a beneficial effect. ${ }^{5-7}$ We therefore examined the relation between the physical activity index and risk of ischaemic heart disease after excluding all men who reported doing sporting (vigorous) exercise at least once a month. The inverse relation was still seen in men without ischaemic 
heart disease and was as strong as that seen when sporting activity was included (table 6) Among men with ischaemic heart disease those who were inactive had slightly higher rates than all other men.

\section{Discussion}

It is widely accepted that physical activity is associated with a beneficial effect on ischaemic heart disease, with most studies showing an increased risk in sedentary subjects compared with "active" subjects. ${ }^{1-817}$ Regular physical activity improves physical fitness, and several researchers have suggested that the effect of physical activity on ischaemic heart disease is determined by its influence on physical fitness. Several recent American studies using objective measures of physical fitness have shown a strong inverse association with the risk of coronary heart disease. ${ }^{18-22}$ Some studies have found that the relation between physical activity patterns and risk of coronary disease diminishes after adjustment for measures of physical fitness. ${ }^{2021}$ The type and level of physical activity in subjects classified as "active" vary considerably in the different studies and there is still debate as to what type, duration, and intensity of physical activity are required to achieve levels of fitness likely to produce a beneficial effect. Studies in British male civil servants suggest that it has to be regular, aerobic, and vigorous exercise to achieve a beneficial effect. ${ }^{2-4}$ In the United States Paffenbarger and colleagues suggested that frequent lighter activities are sufficient to produce a beneficial effect. ${ }^{5}$

\section{BRITISH REGIONAL HEART STUDY}

In the present study physical activity showed a strong inverse association with risk of heart attack. Physical activity was strongly associated with smoking, social class, obesity, and prevalence of pre-existing ischaemic heart disease. Men who were inactive were more likely to be smokers, to be manual workers, and to be obese and had a higher prevalence of preexisting ischaemic heart disease than men who were more active. The inverse association between smoking and physical activity seen in this study is consistent with several other studies. Because the development of ischaemic heart disease is likely to result in changes to the pattern of physical activity, the relation was examined separately in men with and without evidence of ischaemic heart disease. In men with no ischaemic heart disease the risk of heart attack decreased to levels of moderately vigorous activity. Men who carried out moderate or moderately vigorous activity experienced a $50 \%$ reduction in risk compared with inactive men even after adjustment for age, social class, smoking, and body mass index. These are men who tend to be engaged in regular sport at least once a week or who engaged in lighter physical activities regularly throughout the week-for example, walking and weekend activities. Moderate to moderately vigorous levels of activity were not only associated with the reduction of heart attacks but these men were also more likely to survive a heart attack than less active men. However, in men who undertook vigorous levels of activity, the risk of heart attacks increased. These men tend to be engaged in vigorous sport at least three times a week. Though the number of men in this group was small, there is a suggestion that the extremes of vigorous exercise may have adverse effects on the heart, particularly in younger middle-aged men (see addendum).

RISKS OF VIGOROUS EXERCISE

The findings of an increased risk in very vigorous subjects has been reported in several other studies. ${ }^{4722}$ Paffenbarger et al observed an increase in mortality in the top level of energy expenditure-that is, over $3500 \mathrm{kcal} /$ week. ${ }^{5}$ The Puerto Rican Heart Study found an increased risk in the most active group. ${ }^{17}$ In a study of apparently healthy, middle aged men, Erikssen found an increased risk in the most fit men. ${ }^{23}$ In the Multiple Risk Factor Intervention Trial study, although their highest activity category was very broad, they indicated that more vigorous activity did not confer any further protection than did moderately intense activities. ${ }^{7}$ Siscovick $e t$ al found that the risk of primary cardiac arrest is transiently increased during vigorous exercise-that is, risk during exercise among men at the highest level of habitual activity. ${ }^{24}$ There is also growing evidence that strenuous exercise may precipitate sudden death in middle aged men. ${ }^{25}$ The increased risk seen in our study was only evident in the younger men and may reflect the type of sport undertaken (see addendum).

\section{RISK FACTORS AND PHYSICAL ACTIVITY}

Physical activity has been shown to be associated with a favourable influence on risk factors including the reduction of blood pressure and obesity and an increase in high density lipoprotein cholesterol. ${ }^{26}$ In the present study physical activity was associated with a small increase in high density lipoprotein cholesterol that was apparent only at the highest levels of activity. This is consistent with several studies that indicate that only strenuous and aerobic exercise increases high density lipoprotein cholesterol. ${ }^{26}$ There was a small reduction in blood pressure with increasing physical activity, which was stronger for diastolic than for systolic and largely attributable to the reduction in heart rate associated with physical activity. No association was seen between physical activity and serum total cholesterol. The effects of physical activity on these risk factors are small and are unlikely to explain the relation seen. Physical activity was strongly associated with $\mathrm{FEV}_{1}$, which has been shown to be a strong predictor of ischaemic heart disease. $^{15}$ However, even after adjusting in addition for high density lipoprotein cholesterol, systolic blood pressure, total cholesterol, and $\mathrm{FEV}_{1}$ the inverse relation persisted. This is consistent with most other studies showing that the risk of ischaemic heart disease associated with inactivity is attenuated but does not disappear after adjusting for coronary risk fac- 
tors. ${ }^{5-7} 17$ Men who were vigorously active had the most favourable risk factors but their risk was similar to inactive men after adjustment.

\section{PRE-EXISTING ISCHAEMIC HEART DISEASE}

Most prospective studies examining the relation between physical activity and ischaemic heart disease have excluded men with evidence of cardiovascular disease. Little therefore is known about the long term effects of physical activity in the presence of ischaemic heart disease. Evidence on the effect of exercise comes from clinical trials, which overall have been inconclusive. ${ }^{27} \mathrm{~A}$ recent study on physical training in 11 patients with chronic heart failure suggests that exercise training can increase exercise duration and improve symptoms, but such studies provide no information on ultimate outcome. ${ }^{28}$ The inverse pattern clearly seen in men without ischaemic heart disease was not as apparent in men with ischaemic heart disease, though inactive men had the highest risk (fig 5). In men with symptomatic evidence of ischaemic heart disease-that is, those who were aware of their cardiac problem (fig 6)-there was a U-shaped relation, with risk decreasing to levels of light and moderate activity and increasing at more vigorous levels of activity. The implications of this analysis are that light or moderate physical activity in men with symptomatic ischaemic heart disease may be of benefit and that moderately vigorous or vigorous activity may be detrimental. In men with asymptomatic ischaemic heart disease (fig 6) risk tended to increase with increasing activity though the fatality rate decreased. The implication is that although these men achieved increasing cardiopulmonary fitness from increasing physical activity, their risk of heart attack was increased by increasing physical activity.

\section{IS VIGOROUS SPORT ESSENTIAL?}

The most popular physical activity was recreational activity-for example, gardening, do-it-yourself, and pleasure walking. Twenty five percent of the men were engaged in regular (at least once a month) vigorous sporting activity. Results from other British studies have suggested that such aerobic exercise is essential to produce a beneficial effect. ${ }^{4}$ However, when all men who undertook vigorous sport were excluded from the analyses, there was still a strong inverse association, with risk significantly lowered in those who carried out frequent physical activities. Our results accord with those of Paffenbarger et al who suggested that regular frequent activity is associated with a reduced rate of heart attack. Several other American studies have shown moderate levels of activity to be sufficient to produce a beneficial effect ${ }^{5-7}$ and have shown that benefit is derived from non-vigorous leisure activities such as pleasure walking and gardening. In the British Regional Heart Study recreational activity showed the most consistent relation, with heart attack rates decreasing with frequency of these activities and this was apparent both for men with and without ischaemic heart disease. Vigorous sport was beneficial in men without ischaemic heart disease but there was no dose-response relation with increasing frequency and the risk in those engaged in vigorous sport three or more times a week was similar to those who reported no vigorous activity.

\section{IMPLICATIONS AND RECOMMENDATIONS}

Men free of ischaemic heart disease

In this population of middle-aged men, moderate or moderately vigorous physical activity was associated with a significantly decreased risk of heart attack. Moderate physical activity involves frequent recreational activities plus regular walking or vigorous activity once a week. Moderately vigorous activity involves frequent recreational activities, plus cycling or sporting activity at least once a week. However, even if no regular sporting activity is carried out, increasing levels of other forms of physical activity are strongly associated with decreasing risk of heart attack. There seems to be an increased risk of heart attack in younger middle-aged men (40-49) who carry out frequent sporting activity - for example, more than three times a week. While not wishing to sound unduly cautious in an era of jogging, squash, and marathon running, it might be reasonable for men in middle-age considering a programme of vigorous activity to undergo a review of their cardiovascular state. In view of the high prevalence rate of ischaemic heart disease in middle aged British men $^{29}$ this is neither alarmist nor unreasonable (see addendum).

\section{Men with ischaemic heart disease}

In men with symptomatic ischaemic heart disease physical activity at light or moderate levels is associated with a slightly diminished risk of heart attack. At higher levels of physical activity, however, the rate of heart attack increases and is similar to those seen in inactive men. The message to such men is that light or moderate physical activity is likely to be of benefit. However, undertaking vigorous activity may produce ill effects and they would do well to discuss any proposed activity at a higher level with their physician. In men with asymptomatic ischaemic heart disease detected only by routine electrocardiogram-for example, in health checks, screening programmes, or insurance examinations, although the overall rate of heart attack is lower than in men with symptomatic ischaemic heart disease, the risk of heart attack appears to increase with increasing physical activity. The message must be one of reasonable caution.

Our findings accord with the recent report on medical aspects of exercise from the Royal College of Physician of London which emphasises that "the potential benefits must be weighed against the possible provocation of serious cardiac arrhythmias by those who already have coronary artery disease whether or not it has been recognised." ${ }^{30}$ Our findings also suggest that the protective effect is not limited to those taking vigorous aerobic exercise twice weekly and we would encourage a more positive attitude to participation in regular 
moderate activity in all age groups.

The British Regional Heart Study is a British Heart Foundation Research Group and also receives support from the Department of Health and The Chest, Heart and Stroke Association. We are grateful to Dr Peter Macfarlane (Department of Medical Cardiology The Royal Infirmary, Glasow) for the Medical (D) Home and Health Department.

1 Berlin JA, Colditz A. A meta-analysis of physical activity in the prevention of coronary heart disease. Am J Epidemio 1990;132:612-27.

2 Morris JN, Chave S, Adam C, Sirey C. Vigorous exercise in leisure-time and the incidence of coronary heart-disease. Lancet 1973; i:333-9.

3 Morris JN, Everitt MG, Pollard R, Chave SPW, Semmence AM. Vigorous exercise in leisure-time: protection against coronary heart disease. Lancet 1980;ii: 1207-10.

4 Morris JN, Clayton DG, Everitt MG, Semmence AM Burgess EH. Exercise in leisure time: coronary attack and death rates. Br Heart $J$ 1990;63:325-34.

5 Paffenbarger RS, Hyde RT, Wing AL, Hsieh CC. Physical activity, all cause mortality, and longevity of college alumni. N Engl J Med 1986;314:605-13.

6 Slattery ML, Jacobs DR, Nichaman MZ. Leisure time physical activity and coronary heart disease death: the US Railroad Study. Circulation 1989;79:304-11.

7 Leon AS, Connett J, Jacobs DR, Rauramaa R. Leisure time physical activity levels and risk of coronary heart disease and death: MRFIT. JAMA 1987;258:2388-95.

8 Salonen JT, Slater JS, Tuomilehto J, Rauramaa R. Leisure time and occupational physical activity: risk of death from ischaemic heart disease. Am J Epidemiol 1988;127:87-94.

Shaper AG, Pocock SJ, Walker M, Cohen NM, Wale CJ, Thomson AG. British Regional Heart Study: cardio-
vascular risk factors in middle-aged men in 24 towns. vascular risk factors in

10 Thelle DS, Shaper AG, Whitehead TP, Bullock DG, Ashby D, Patel I. Blood lipids in middle-aged British men. $B r$ Heart $J$ 1983;49:205-13.

11 Cook DG, Shaper AG, Macfarlane PW. Using the WHO (Rose) angina questionnaire in cardiovascular epidemiological studies. Int J Epidemiol 1989;18:607-13.

12 Wilson PWF, Paffenbarger RS, Morris JN, Havlik RJ. Assessment methods for physical activity and physical fitness in population studies: report of a NHL BI workshop. Am Heart J 1986;111:1177-92.

13 Taylor HL, Jacobs DR, Schucker B, Knudsen J, Leon AS, Debacker $G$, et al. A questionnaire for the assessment of leisure time physical activities. J Chronic Dis 1978;31: 741-55.

14 Blair SN, Kannel WB, Kohl HW, Goodyear N, Wilson PWF. Surrogate measures of physical activity and physical fitness. Evidence for sedentary traits of resting tachycardia, obesity and low vital capacity. Am J Epidemiol 1989;129:1145-6.
15 Cook DG, Shaper AG. Breathlessness, lung function and the risk of heart attack. Eur Heart $J 1988 ; 9: 1215-22$.

16 Kannel WB, Kannel C, Paffenbarger RS, Cupples LA. Hear rate and cardiovascular mortality: The Framingham Study. Am Heart J 1987;113:1489-94.

17 Garcia Palmieri MR, Costas R, Cruz-Vidal M, Sorlie P Havlik RJ. Increased physical activity: a protective facto against heart attacks in Puerto Rico. Am J Cardiol 1982;50:749-55.

18 Peters RK, Cady LD, Bischoff DP, Bernstein L, Pike MC Physical fitness and subsequent myocardial infarction in healthy workers. JAMA 1983;249:3052-6.

19 Ekelund LG, Haskell WL, Johnson JL, Whaley FS, Criqui MH, Sheps DS. Physical fitness as a predictor of cardiovascular mortality in asymptomatic North American men. Lipid Research Clinics Mortality Follow-up Study. N Engl J Med 1988;319:1379-84.

20 Slattery ML, Jacobs DR. Physical fitness and cardiovascular disease mortality: the US Railroad Study. Am J Epidemiol disease mortality:

21 Sobolski J, Kornitzer M, de Backer G, Dramaix M, Abramowicz M, Degre S, et al. Protection agains ischaemic heart disease in the Belgian physical fitnes study: physical fitness rather than physical activity. $A m$ Epidemiol 1988;125:601-10.

22 Blair SN, Kohl H III, Paffenbarger RS, Clark DG, Coope $\mathrm{K}$, Gibbons LW. Physical fitness and all-cause mortality. $J A M A$ 1989;262:2395-401.

23 Erikssen J. Physical fitness and coronary heart disease morbidity and mortality: a prospective study in apparently healthy, middle-aged men. Acta Med Scand 1986;(suppl 711):189-92.

24 Siscovick DS, Weiss NS, Fletcher RH, Lasky T. The incidence of primary, Fletcher RH, Lasky T. The incidence of primary cardiac arrest

25 Oberman A. Exercise and the primary prevention of cardiovascular disease. Am J Cardiol 1985;55:10D-20D.

26 Folsom AR, Caspersen CJ, Taylor HL, Jacobs DR, Luepke RV, Gomez-Marin $O$. Leisure time physical activity and its relationship to coronary risk factors in a population based sample: the Minnesota Heart Survey. Am Epidemiol 1985;121:570-9.

27 Naughton J. Role of physical activity as a secondary intervention for healed myocardial infarction. $A m$ Cardiol 1985;55:21D-6D

28 Coats AJ, Adamopoulos S, Meyer T, Conway J, Sleight P. Effects of physical training in chronic heart failure. Lancet 1990;335:63-6.

29 Shaper AG, Cook DG, Walker M, Macfarlane PW. Prevalence of ischaemic heart disease in middle aged Prevalence of ischaemic heart disease in middle aged

30 Royal College of Physicians of London. Medical aspects of exercise; benefits and risks. 1991.

\section{Addendum}

Further analyses strongly suggest that the increased risk of heart attack in men without ischaemic heart disease involved in vigorous levels of physical activity may reflect the presence of hypertension in addition to the type and degree of sporting exertion. This possibility is now being fully examined. 
such patients. To retain the confidentiality of our database we undertook the mailing ourselves.

Do not forget the date for our first teach-in, announced in the December newsletter. This new programme is intended to update members of the society in growing points of modern medicine that are intimately related to our specialty. Sir David Weatherall will be arranging the first meeting (on molecular biology) on Tuesday 31 March from 10 am to $4 \mathrm{pm}$. A subsidy will be available for longdistance travel within the United Kingdom. We intend that these meetings should be small to encourage interaction with the speakers. There will not be another similar opportunity for a very long time. Contact the society at once if you wish to reserve a placebut you may already be able to secure a place on the reserve list only ... Please note that the meetings are exclusively for members.

Copies are now available from the society offices of the Fourth Report of a Joint Cardiology Committee of the Royal Colleges of Physicians of London and the Royal College of Surgeons of England on the provision of services for the diagnosis and treatment of heart disease. The college reports are authoritative documents that can be of great value to those who have to persuade managers of the basic requirements of a cardiology service.

Another date for many diaries, and again we expect demand to exceed supply: Resuscitation '92 will be the first CPR congress of the European Resuscitation Council (the British Cardiac Society was prominent in the formation of the European Resuscitation Council which is now gaining wide acceptance in Europe). An excellent international programme has been arranged in cooperation with the Resuscitation Council of the United Kingdom. The meeting will take place in the Brighton Centre. All the indications show this will be a popular meeting and many delegates are expected from mainland Europe. Application forms can be obtained from the society office.

Remember to note our new address given below. And again for reference our new telephone number is: 0713833887 . Note that our fax number has a slightly different exchange code: 0713880903 .

DOUGLAS CHAMBERLAIN President, British Cardiac Societ PAUL OLDERSHAW Secretary, British Cardiac Society 9 Fitzroy Square,
London W1P $5 A H$

\section{NOTICE}

\section{2}

The Annual Meeting of the British Cardiac Society will take place at the Harrogate International Centre on 26 to 29 May. The closing date for receipt of abstracts was 3 January.

\section{CORRECTIONS}

Staffing in cardiology in the United Kingdom. Sixth biennial survey: with data on facilities in cardiology in England and Wales 1989

(November issue, volume 66: pages 395-404) The President of the British Cardiac Society has asked us to point out that table 13 showed an incorrect total under the number of consultants retiring from 1991 to 1995 , though the data for individual years were correct. This total was inadvertently left unchanged when one year was removed from the table shortly before the paper was submitted.

Table 16 showed the number of technicians in the Regions of England and Wales, and these figures were correct according to the returns received. But the calculations for numbers per 250000 were incorrect-the true totals were slightly higher. This error represents a complex calculation based on the premise that the need for technician time is not related in a linear fashion to population. These figures were derived for another purpose but were inadvertently substituted for the original calculations that had been correctly made.

Physical activity in ischaemic heart disease in middle-aged British men. $A G$ Shaper, $G$ Wannamethee (November issue, volume 66: pages 384-94). The authors have asked us to point out that $R$ Weatherall was inadvertently omitted from the authorship of this paper which is $A G$ Shaper, $G$ Wannamethee, $R$ Weatherall. 